\title{
Can Cushioned Shoes with Anatomical Insole Correct the Impact in Runners with Recurring Shin Splint?
}

\author{
Carlos I De la Fuente ${ }^{1,2,3,6 *}$, Hugo Henríquez ${ }^{1}$, Rodrigo Ramírez-Campillo ${ }^{4,5}$, Mauricio Delgado ${ }^{2,3}$, \\ Claudio Chamorro ${ }^{2}$, Sebastian Ruidiaz ${ }^{1}$, Christian Campos ${ }^{2}$ and Giovanni Carcuro ${ }^{1}$ \\ ${ }^{1}$ Foot and Ankle unit, Instituto Traumatológico, "Teodoro Gebauer Weisser", Santiago, RM, Chile \\ ${ }^{2}$ Carrera de kinesiologia, UDA Cs Salud, Facultad Medicina, Pontificia Universidad Catolica de Chile, Santiago, RM, Chile \\ ${ }^{3}$ Kinesiology and Clinical Biomechanics Master Program, UMCE, Santiago, RM, Chile \\ ${ }^{4}$ Department of Physical Education, Sport and Recreation, Universidad de La Frontera, Temuco, Chile \\ ${ }^{5}$ Department of Physical Activity Science, Universidad de Los Lagos, Osorno, Chile \\ ${ }^{6}$ Mechanical engineer student, USACH, Santiago, RM, Chile
}

Received: October 18, 2014; Accepted: January 09, 2015; Published: February 05, 2015

*Corresponding author: Carlos I De la Fuente, Foot and Ankle unit, Instituto Traumatológico “Teodoro Gebauer Weisser", San Martin 771, Santiago, RM, Chile, Tel: +056-09-54265340; Email: delafuentte@gmail.com

\begin{abstract}
Shin splint injury usually takes several weeks to recover. We determine the effect of cushioned shoes with anatomical insole on impact, over pronation and mechanical strategy to impact during running in $10 \mathrm{k}$ runners, over pronators, rear foot initial contact and unilateral recurrent shin splint respect bare foot running before sport return.

Fourteen runners with recurrent shin splint who underwent standardized physical therapy were included. We compared by one tailed paired t-test the variables impact, rear foot over pronation angle in midstance and mechanical strategy to impact during barefoot running condition with anatomical insole and cushioned shoes running condition ( $\alpha=0.05$ and $1-\beta=80 \%)$.

The impact was reduced from $6.893 \mathrm{~g}$ to $6.600 \mathrm{~g}$ (95\% CI: 6.513 g-6.686 g, $p<0.001$ ) using cushioned shoes with anatomical insole condition respect barefoot running condition. The over pronation angle in midstance was reduced from $18.50^{\circ}$ to $16.21^{\circ}$ (95\% CI: $14.29^{\circ}-18.13^{\circ}, p=0.011$ ) using cushioned shoes with anatomical insole condition respect barefoot running condition. The mechanical strategy to impact analyzed by cross correlation coefficient between cushioned shoes with anatomical insole condition with barefoot running condition was 0.77 (95\% CI: 0.74-0.81, p<0.001). Running with cushioned shoes with anatomical insole in subjects with unilateral recurrent shin splint before return sport attenuates the impact and reduces over pronation. But, doesn't change the mechanical strategy to impact.
\end{abstract}

Keywords: Shin splint; Running, Impact, Iso-inertial accelerometer

\section{Introduction}

Detmer [1] in 1986 includes shin splint, tibial stress fracture and periostitis as Medial Tibial Stress Syndrome (MTSS). This involves a progression from acute inflammation to local anabolic bone reaction [2-4] that ends in structural bone damage [4,5]. Although primary cause of MTSS is unknown $[3,6,7]$, radiology findings show a progressive bone reaction [6] related to impact and running $[8,9]$. Related risk factors are over pronation, initial rear foot contact, muscle fatigue or previous MTSS.

The impact (i.e. "the collision between two objects" [10]), is habitually associated with MTSS $[6,8]$. Tibial impact during running occurs 150 milliseconds after heel contact [11], with potential harmful effects in runners $[8,12]$. Low cost accelerometers can be used to assess impact in running [13-15] and helps to study mechanical patterns [15-18]. Heel contact has a correlation coefficient of $87 \%$ with ground reaction force [18].

Recently, 10 kilometers (10 k) running are massive and inexpensive [19]. Unfortunately, between 27 to $70 \%$ of $10 \mathrm{k}$ runners may develop MTSS [20,21]. Recovery of 18 minutes of asymptomatic running may take more than 100 days to return to sport after MTSS [6]. Today, there is not enough information related to recovery or MTSS re-injury process, but physicians and physical therapist usually recommends changing footwear and use an orthopedics insole [3] in order to reduce impact. However, it is not know if this therapeutic management positively affects the mechanical characteristics of impact during running [6].

Therefore, our research aim was to determine the effect of cushioned shoes with anatomical insole on impact, over pronation and mechanical strategy to impact during running in $10 \mathrm{k}$ runners, over pronators, rear foot initial contact and unilateral recurrent shin splint respect barefoot running before sport return.

\section{We hypothesized that:}

1. Impact during running is lower using anatomical insole with cushioning shoes compared to bare foot running.

2. The over pronation angle in midstance is lower using anatomical insole with cushioned shoes compared to barefoot running. 
3. Exist a change of mechanical strategy to impact using anatomical insole with cushioned shoes respect to barefoot running (cross-correlation coefficient $<70 \%$ ).

\section{Methods}

\section{Study design}

This prospective, single-blind trial and analytic observational study was conducted in Instituto Traumatológico "Teodoro Gebauer Weisser" (Santiago, Chile).

\section{Subjects}

Fourteen consecutive male rear foot runners and over pronators with recurrent unilateral shin splint diagnosis (Table 1) who underwent a physical therapy process (Table 2) were incorporated into the study during June 2013 to September 2014. No patient was excluded or lost during the study. A priori, the sample size necessary to obtain a statistical power of $80 \%$ with $5 \%$ of type I error in difference between two dependent means (matched pairs) of one tail, was twelve subjects being developed by G*Power 3.1.9.2 (Kiel University, Germany).

The inclusion criteria was men between 20 and 45 years of age, diagnosis of recurrent shin splint disorder (posteromedial pain of distal tibial portion during exercises), at least 2 episodes

Table 1: Subject characteristics.

\begin{tabular}{|l|l|l|}
\hline Total subject, $\mathrm{n}=14$ & Mean & S.D \\
\hline Age (years) & 31.7 & $(10.3)$ \\
Height $(\mathrm{m})$ & 1.74 & $(0.04)$ \\
Weight $(\mathrm{Kg})$ & 72.8 & $(6.2)$ \\
Body mass index $(\mathrm{Kg} / \mathrm{m} 2)$ & 23.8 & $(2.2)$ \\
Initial contact frequency (Initial contact/s) & 0.76 & $(0.12)$ \\
\hline
\end{tabular}

S.D. $=$ standard deviation

Table 2: Physical therapy treatment.

\begin{tabular}{|c|c|}
\hline Period & Therapeutic principles \\
\hline Week 1 & $\begin{array}{l}\text {-Sport rest } \\
\text {-Control of inflammatory reaction (Compression ban- } \\
\text { dages) } \\
\text {-Control of pain (cryotherapy and TENS) } \\
\text {-Plantar flexion flexibilization (superficial thermotherapy } \\
\text { and PNF) }\end{array}$ \\
\hline Week 2 to 5 & $\begin{array}{l}\text { - Maintence control of inflammatory reaction and pain } \\
\text { - Improve ankle muscle flexibility } \\
\text { - Isometric strengthening } \\
\text { - Start excursion training } \\
\text { - Progression of isometric strengthening to eccentric } \\
\text { strengthening }\end{array}$ \\
\hline Week 6 & $\begin{array}{l}\text {-Maintence flexibilization improved } \\
\text {-Aerobic reconditioning } \\
\text {-Footwear modification (footprint analysis) } \\
\text {-Eccentric strengthening (emphasis on inverter group) } \\
\text {-Start of the running on treadmill } \\
\text { Add } 5 \text { minutes per session } \\
\text { Cryotheraphy after running training }\end{array}$ \\
\hline Week 7 & $\begin{array}{l}\text {-Achieve } 20 \text { minutes of running without presence of pain } \\
\text {-Running analysis } \\
\text {-Advance towards to the sport return stage }\end{array}$ \\
\hline
\end{tabular}

TENS = Transcutaneous Electrical Nerve Stimulation; PNF = Propioceptive Neuromuscular Facilitation. of shin splint in the last year, $10 \mathrm{k}$ runners, rear foot initial contact runner, barefoot over pronation over $15^{\circ}$ during midstance running [22] and asymptomatic running of 20 minutes at seventh week of physical therapy. The exclusion criteria was any lower limb musculoskeletal injury, pain at moment of running analysis, cognitive impairments or any other conditions that alter the running analysis. All subjects gave their consent to the study. This was approved by IRB of Instituto Traumatológico "Teodoro Gebauer Weisser" (Santiago, Chile) according to the principles of Helsinki declaration. Written informed consent was obtained from all participants.

\section{Intervention}

Medical diagnosis was developed by two senior foot and ankle orthopedic surgeons. After medical diagnosis, all subject received $400 \mathrm{mg}$ every 8 hours during first 5 days to reduce the acute symptoms with non steroidal anti-inflammatory drug (2-(4-isobutylphenyl) propionic acid) by oral way. The last two days, in all subjects it was indicated progressively reduce the frequency of drug administration.

Each subject completed a physical therapy process for 7 weeks developed by the same therapist (CD), by attending sessions of 1.5 hours 3 times a week.

A footprint correction was done with neutral cushioned shoes (Asics America Corp., USA) with anatomic insole (Foot Solution, Chile). The insole was designed using pedobarography data (RScan international NV, Belgium), aimed at diminish pressure in footprint (Figure 1) with wedges and arches. The insole was created by a senior foot specialist (Foot Solution, Chile) with the same materials. Seven days before the evaluation, all subjects used the anatomic insole for least two hours every day.

\section{Assessment}

A running analysis with accelerometer and videophotogrammetry by Matlab 7.0.1 (Mathworks inc., USA) was done in the Biomechanics unit of Centro de Investigaciones Medicas del Instituto Traumatológico "Teodoro Gebauer Weisser" (Santiago, Chile) by the same evaluator (CD). Each subject ran with cushioned shoes with anatomical insole and barefoot. They started with a 2 minute warm up at $3.0 \mathrm{~m} / \mathrm{s}$. If they needed more time to get used to the treadmill (Techno gym Spa, Italy) they practiced more time. Once the warm up was over, they selected their own speed to run. The speed was similar to the speed they used to practice before the shin injury. Randomly they were allocated to either start running with cushioned shoes with anatomic insole condition or running barefoot condition. Each condition was 5 minutes of time duration. The subjects had 10 minutes of rest between conditions. A triaxial accelerometer ADXL 345 (Analog Devices Inc., USA) with $16 \mathrm{~g}, 3.9 \mathrm{mg} / \mathrm{LSB}$ of resolution, wireless connection and amplified by a factor of 10 [9] was used. The accelerometer was fixed to the calcaneus in bipedal posture respect its medio-lateral axis and cephalo-caudal axis. In a static way the sensor was calibrated by the action of the gravity force in $\mathrm{X}, \mathrm{Y}$ and $\mathrm{Z}$ versors. In a dynamic way each signal was taken in a sample frequency of $1000 \mathrm{~Hz}$. 


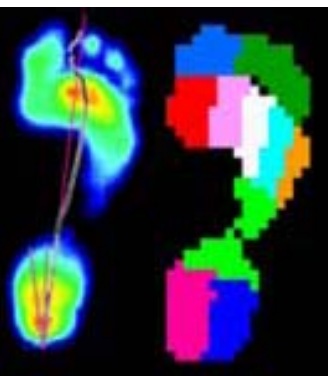

A)

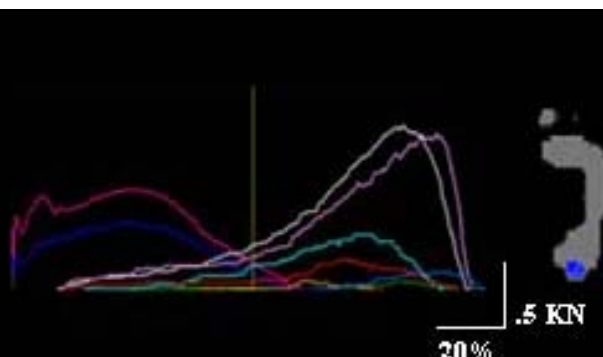

$\mathbf{2 0} \%$



B)

Figure 1: Pedobarography assessment. Two subjects during pedobarography assessment, (A) a rearfoot overpronation (Pink line) with cavus footprint impression (false cavus) during pedobarography at left and ground reaction force by footprint area at right, (B) a medial impact during rearfoot overpronation into the first 150 miliseconds of running. $\mathrm{KN}=$ Kilo Newton.
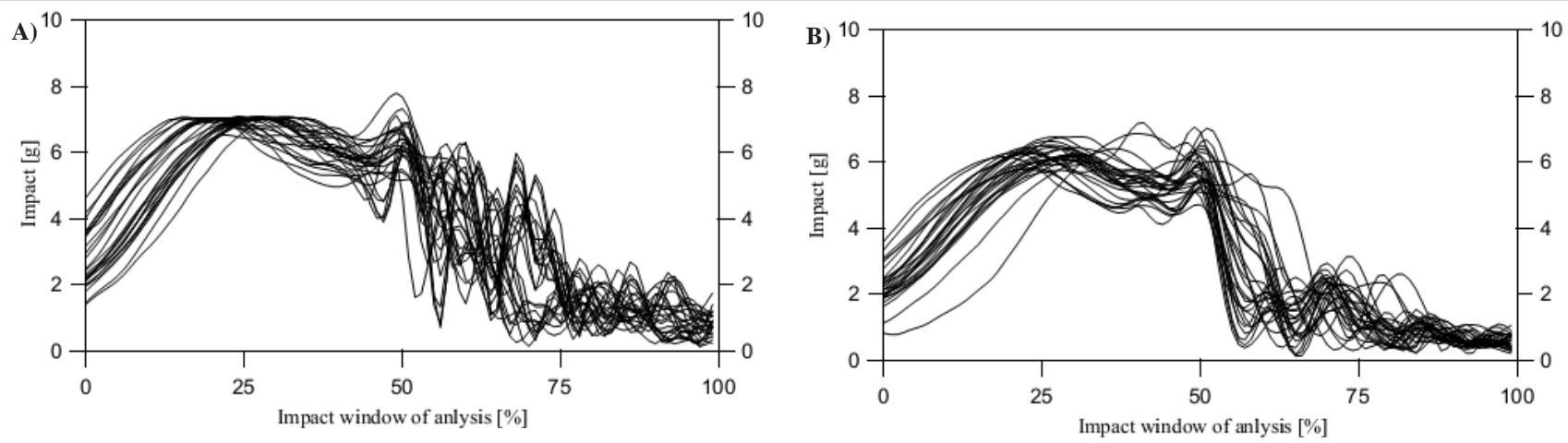

Figure 2: Impact signal. Impact signal of one subject, (A) barefoot condition. (B) cushioned shoes with anatomical insole condition.

\section{Outcomes}

Thirty consecutive initial contacts were identified from a frequency analysis using a wavelet transform described by Aung et al. [15] in relation to the accelerometer signal using a Daubechies 4 by Mat lab 7.0.1 (Mathworksinc, USA). After that, to create the impact signal from the initial contact we made a normalized analysis (second/second) at $100 \%$ of the 150 milliseconds starting at the initial contact of the isoinertial signal (Figure 2). The maximum value of the impact signal (equation 1) was used to obtain the impact variable for cushioned shoes with anatomic insole and barefoot condition.

To quantify the mechanical strategy change during impact, each impact signal of two conditions was cross-correlated (equation 2) [23] to obtain a mechanical strategy to impact variable. A correlation coefficient of 0.7-1.0 was considered as a strong correlation [24].

Thirty over pronation rare foot angles in midstance by two dimensional methods as described by Nigg [22] were averaged to obtain the over pronation angle in midstance variable for cushioned shoes with anatomical insole condition and bare foot condition.

$$
\operatorname{Impact}[\mathbf{T}]=\sqrt[2]{a_{x}[\mathbf{T}]^{2}+a_{y}[\mathbf{T}]^{2}+a_{z}[\mathbf{T}]^{2}}
$$

$$
\mathbf{r}_{\mathrm{XY}}[\mathbf{T}]=\int_{0}^{T} \mathbf{X}[\mathbf{T}] \mathbf{Y}[\mathbf{T}+\tau] \mathbf{d t} / \mathbf{T}^{*} \sqrt{\int \mathbf{X}[0] \mathbf{X}[\tau] \mathbf{d t} * \int \mathbf{Y}[0] \mathbf{Y}[\tau] \mathbf{d t}}
$$

Where Impact [T] is the isoinertial accelerometer signal, $\mathrm{a}_{x}[\mathrm{~T}]$ is the cephalo-caudal rear foot signal, $\mathrm{a}_{\mathrm{y}}[\mathrm{T}]$ is the medio-lateral rear foot signal, $\mathrm{a}_{\mathrm{z}}[\mathrm{T}]$ is the antero-posterior rear foot signal, $\mathrm{X}[\mathrm{T}]$ is the barefoot condition, $\mathrm{Y}[\mathrm{T}]$ is the cushioned shoes with anatomical insole condition and $\mathrm{T}$ is time.

\section{Statistical analysis}

In total, 2520 impact signals (14 runners $\mathrm{x} 2$ conditions $\mathrm{x}$ 3 channels x 30 running cycles) were analyzed by STATA 12.0 (Stata Corp., EEUU). We used the Shapiro Wilk test to see if there was a normal distribution of the variables. After that, we studied if there was equal or different variance between groups. As data were normally distributed and with equal variance we used one tailed paired t-test with I type error of $5 \%$, to compare the cushioned shoe with anatomical insole condition and barefoot condition.

\section{Results}

Impact was reduced from $6.893 \mathrm{~g}$ to $6.600 \mathrm{~g}(95 \% \mathrm{CI}$ : 6.513 g-6.686 g) using cushioned shoes with anatomical insole (Table 2) with $\mathrm{p}<0.001$, accepting our null hypothesis (1). Over pronation angle in midstance was reduced from $18.50^{\circ}$ to $16.21^{\circ}$ 
(95\% CI: $14.29^{\circ}-18.13^{\circ}$ ) using cushioned shoes with anatomical insole (Table 2) with $\mathrm{p}=0.011$, accepting our null hypothesis (2). We found a correlation coefficient of 0.77 using cushioned shoe with anatomical insole (Table 2 ) with $\mathrm{p}<0.001$, rejecting our null hypothesis (3).

\section{Discussion}

Correcting the impact is essential to avoid a new shin splint injury [25]. Rest and using insole are common ways of treating MTSS, but they have not shown to be too successful [26,27]. It is not known if anatomical insole can correct the impact during running and actually there is not enough scientific evidence available to support the prescription of using cushioned shoes, anatomical insole or their combination [28]. The objective of our research was to determine the effect of cushioned shoes with anatomical insole on impact, over pronation and mechanical strategy to impact during running in $10 \mathrm{k}$ runners, over pronators, rear foot initial contact and unilateral recurrent shin splint, respect barefoot running, before sports return.

We acknowledge the limitations of our study. First, we used a two dimensional video photogrammetry method to obtain over pronation angle, but we could have created sensor with inclinometer and magnetometer to obtain directly the over pronation angle without video photogrammetry analysis. Second, we could have attached multiples sensors on bony segments calculated the attenuation phenomena arisen from rear foot to tibia with elastic wave propagation principles. Third, we could describe the pathological kinematic pattern of lower limb to know more details of pathological motion. Fourth, our physical therapy intervention had general principles to treat MTSS.

We found it is possible reduce impact and the over pronation angle using cushioned shoes with anatomical insole while running compared to running barefoot condition, after shin splint injury. But, the cushioned shoes with anatomical insole were not capable of changing the mechanical strategy to impact.

Increased over pronation angle was described by Gallant et al. [7] as a risk factor for shin splint. Stacoff et al. [29] published that foot orthesis could reduce only 1 to $4^{\circ}$ of the over pronation angle with a small kinematic effect, showing similar results with us. By the way, Lafortune et al. [30] and Akins et al. [31] published that impact was reduced using insole, which agree with our findings and suggest the use of proper insole for running reduce risk factors of a new MTSS compared to barefoot condition after the rehabilitation of shin splint injury. In our case, the appropriate insole design was made with a pedobarography analysis.

Nevertheless, a mechanical strategy to impact is not changed during running while using cushioned shoes with anatomic insole after our physical therapy intervention (Table 3 and Figure 2).This warms that maintaining mechanical behavior from impact was not different to obtained during barefoot condition. This agrees with the report of Nigg et al. [32], who found that anatomic insoles had an influence on the magnitude of impact, but not in its loading rate. This also agrees with Davies et al. [33], who reporting that runners that produced tibial stress fractures had an increase load of vertical force.
In contrast to our physical therapy intervention, Crowell et al. [25] in 2010 \& Crowell et al. [34] in 2011 demonstrated that a physical therapy with emphasis on changing kinematic strategy through real-time visual feedback with accelerometers reduce the magnitude and change in the mechanical strategy to impact, reducing the risk of tibial overload. Therefore a specific physical therapy is needed regarding the impact during running. Unfortunately, there is no accord in which is the best way to treat medically and with physical therapy, and future research in this areas are recommended to reduce risk factor of new shin splint injury after their rehabilitation. Because as we found, cushioned shoes with anatomical insole alone with our physical therapy intervention (unspecific physical therapy) for impact are insufficient to protect against tibial overload.

\section{Conclusion}

In anatomical insole design with cushioned shoes after physical therapy in subjects with unilateral recurrent shin splint before sport return, attenuate the impact and reduce over pronation angle of rear foot during running. Nonetheless, the mechanical strategy to impact does not change respect barefoot condition. This suggests only management with cushioned shoes and anatomical insole design with unspecific physical therapy can creates a mechanical risk of developing a new shin splint injury and progression to stress fracture in distance runners. We suggest create new therapeutic management with cushioned shoes with anatomical insole in recurring shin splint with specific impact running training to decrease the risk of developing new tibial lesions.

\section{Ethical board review statement}

This study was approved by Instituto Traumatológico Institutional Review Board (IRB).

\section{References}

1. Detmer DE. Chronic shin splints. Classification and management of medial tibial stress syndrome. Sport Med. 1986; 3(6):436-46.

2. Magnusson HI, Westlin NE, Nyqvist F, Gärdsell P, Seeman E, Karlsson MK. Abnormally decreased regional bone density in athletes with medial tibial stress syndrome. Am J Sport Med. 2001; 29(6):712-5.

3. Reshef N, Guelich DR. Medial tibial stress syndrome. Clin Sports Med. 2012; 31(2):273-90. doi: 10.1016/j.csm.2011.09.008.

4. Hume P, Hopkins W, Rome K, Maulder P, Coyle G, Nigg B. Effectiveness of foot orthoses for treatment and prevention of lower limb injuries: a review. Sport Med. 2008; 38(9):759-79.

5. Altman AR, Davis IS. Barefoot running: biomechanics and implications for running injuries. Curr Sport Med Rep. 2012; 11(5):244-50. doi: 10.1249/JSR.0b013e31826c9bb9.

6. Newman P, Witchalls J, Waddington G, Adams R. Risk factors associated with medial tibial stress syndrome in runners: a systematic review and meta-analysis. Open Access J Sport Med. 2013; 13(4):22941. doi: 10.2147/OAJSM.S39331.

7. Gallant JL, Pierrynowski MR. A theoretical perspective on runningrelated injuries. J Am Podiatr Med Assoc. 2014; 104(2):211-20. doi: 10.7547/0003-0538-104.2.211.

8. Lieberman DE, Venkadesan M, Werbel WA, Daoud AI, D'Andrea S, 
Davis IS, et al. Foot strike patterns and collision forces in habitually barefoot versus shod runners. Nature. 2010; 28(7280):531-5. doi: $10.1038 /$ nature 08723 .

9. Gruber AH, Boyer KA, Derrick TR, Hamill J. Impact shock frequency components and attenuation in rearfoot and forefoot running. J Sport Heal Sci. 2014; 3:113-21. doi:10.1016/j.jshs.2014.03.004.

10. Nigg BM. Impact forces in running. Curr Opin Orthop. 1997; 8(6):43-7.

11. Robertson G, Caldwell G, Hamill J, Kamen G, Whittlesey S. Research Methods in Biomechanics. 2nd ed. USA: Human Kinetics; 2013.

12. Wakeling JM, Liphardt AM, Nigg BM. Muscle activity reduces softtissue resonance at heel-strike during walking. J Biomech. 2003; 36(12):1761-9.

13. Ledoux WR, Hillstrom HJ. Acceleration of the calcaneus at heel strike in neutrally aligned and pes planus feet. ClinBiomech (Bristol, Avon). 2011; 16(7):608-13.

14. O’Connor CM, Thorpe SK, O’Malley MJ, Vaughan CL. Automatic detection of gait events using kinematic data. Gait Posture. 2007; 25(3):469-74.

15. Aung MS, Thies SB, Kenney LP, Howard D, Selles RW, Findlow AH, et al. Automated detection od instantaneous gait events using time frecuency analysis and manifold embedding. IEEE Trans Neural Syst Rehabil Eng. 2013; 21(6):908-16. doi: 10.1109/TNSRE.2013.2239313.

16.Zijlstra W, Hof AL. Assessment of spatio-temporal gait parameters from trunk accelerations during human walking. Gait Posture. 2003; 18(2):1-10

17. Kavanagh JJ, Menz HB. Accelerometry: a technique for quantifying movement patterns during walking. Gait Posture. 2008; 28(1):1-15. doi: 10.1016/j.gaitpost.2007.10.010.

18. Lord S, Rochester L, Baker K, Nieuwboer A. Concurrent validity of accelerometry to measure gait in Parkinsons Disease. Gait Posture. 2008; 27(2):357-9.

19. Hespanhol Junior LC, Costa LO, Carvalho AC, Lopes AD. A description of training characteristics and its association with previous musculoskeletal injuries in recreational runners: a cross-sectional study. Rev Bras Fisioter. 2012; 16(1):46-53.

20. Hreljac A. Etiology, prevention, and early intervention of overuse injuries in runners: a biomechanical perspective. Phys Med Rehabil Clin N Am.2005; 16(3):651-67.

21. van Gent RN, Siem D, van Middelkoop M, van Os AG, Bierma-Zeinstra SM, Koes BW. Incidence and determinants of lower extremity running injuries in long distance runners: a systematic review. Br J Sports Med.
2007; 41(8):469-80.

22. Nigg BM. Biomechanics of sport shoes. Canada: University of Calgary; 2010.

23. Oda S, Moritani T. Cross-correlation of bilateral differences in fatigue during sustained maximal voluntary contraction. Eur J Appl Physiol Occup Physiol. 1995; 70(4):305-10.

24. Taylor R. Interpretation of the correlation coefficient: a basic review. JDMS.1990; 6(1):35-9. doi: 10.1177/875647939000600106.

25. Crowell HP, Milner CE, Hamill J, Davis IS. Reducing impact loading during running with use of real-time visual feedback. J Orthop Sports PhysTher. 2010; 40(4):206-13. doi: 10.2519/jospt.2010.3166.

26. Schwellnes MP, Jordaan G, Noakes TD. Prevention of common overuse injuries by the use of shock absorbing insoles. A prospective study. Am J Sports Med. 1990; 18(6):636-41.

27. Andrish JT, Bergfeld JA, Walheim J. A prospective study on the management of shin splints. J Bone Joint Surg Am. 1974; 56(8):1697700 .

28. Fong Yan A, Sinclair PJ, Hiller C, Wegner C, Smith RM. Impact attenuation during weight bearing activities in barefoot vs. shod conditions: a systematic review. Gait Posture. 2013; 38(2):175-86. doi: 10.1016/j.gaitpost.2012.11.017.

29. Stacoff A, Reinschmidt C, Nigg BM, van den Bogert AJ, Lundberg A, Denoth J, et al. Effects of foot orthoses on skeletal motion during running. Clin Biomech (Bristol, Avon). 2000; 15(1):54-64.

30. Lafortune MA, Henning EM. Cushioning properties of footwear during walking: accelerometer and force platform measurments. Clin Biomech (Bristol, Avon). 1992; 7(3):181-4. doi: 10.1016/02680033(92)90034-2.

31. Akins JS, Keenan KA, Dugan BP, Francis M, Abt JP, Sell TC, et al. Comparison of plantar pressure measurements obtained during barefoot and shod conditions. Clin Biomech (Bristol, Avon). 2011; 26(6):696-7.

32. Nigg BM, Liu W. The effect of muscle stiffness and damping on simulated impact force peaks during running. J Biomech. 1999; 32(8):849-56.

33. Davis I, Milner CE, Hamill J. Does increased loading during running lead to tibial stress fractures? A prospective study. Med Sci Sports Exerc. 2004; 36(5):S58-S58.

34. Crowell HP, Davis IS. Gait retraining to reduce lower extremity loading in runners. Clin Biomech (Bristol, Avon). 2011; 26(1):78-83. doi: 10.1016/j.clinbiomech.2010.09.003. 